\title{
Pemetaan SMA/SMK Di Kabupaten Minahasa Tenggara Berdasarkan Empat Indikator Standar Nasional Pendidikan Dengan Menggunakan Analisis Biplot
}

\author{
Chandra Purwanto ${ }^{1}$, Djoni Hatidja ${ }^{2}$, Marline Paendong ${ }^{3}$ \\ ${ }^{1}$ Program Studi Matematika, FMIPA, UNSRAT, chandrapurwanto@rocketmail.com \\ ${ }^{2}$ Program Studi Matematika, FMIPA, UNSRAT, dhatidja@yahoo.com \\ ${ }^{3}$ Program Studi Matematika, FMIPA, UNSRAT, marline.paendong16@gmail.com
}

\begin{abstract}
Abstrak
Analisis Biplot merupakan Analisis statistika deskriptif dimensi ganda yang menyajikan secara simultan n objek pengamatan dan $\mathrm{p}$ peubah dalam suatu grafik pada suatu bidang dua dimensi, sehingga ciri-ciri dan posisi relatif peubah tersebut dapat dianalisis.Tujuan penelitian ini adalah: 1) mendeskripsikan karakteristik/mutu dari SMA/SMK di Kabupaten Minahasa Tenggara berdasarkan empat indikator standar nasional pendidikan, yaitu: Standar Isi, Standar Pendidikan dan Tenaga Kependidikan, Standar Sarana dan Prasarana, dan Standar Pengelolaan; 2) melakukan pemetaan, baik keunggulan maupun kekurangan dari SMA/SMK di Kabupaten Minahasa Tenggara berdasarkan indikator standar Nasional Pendidikan dengan menggunakan Analisis Biplot. Data Penelitian ini diperoleh dari populasi 15 SMA/SMK di Kabupaten Minahasa Tenggara sebagai Objek yang diamati. Peubah yang digunakan adalah Peubah Standar Isi, Peubah Standar Pendidikan dan Tenaga Kependidikan, Peubah Standar Sarana dan Prasarana, dan Peubah Standar Pengelolaan. Analisis data dilakukan dengan menggunakan perangkat lunak statistika. Hasilnya menunjukkan bahwa SMA/SMK yang dikategorikan memiliki keunggulan terhadap keempat indikator standar nasional pendidikan adalah SMA Negeri 1 Ratahan, SMK Negeri 1 Ratahan, SMK Negeri 1 Pusomaen, SMA Negeri 1 Touluaan, SMK Negeri 1 Touluaan, SMA Negeri 1 Tombatu, SMK Kristen Tombatu, SMA Negeri 1 Belang. Sedangkan SMA/SMK yang dikategorikan memiliki standar yang kurang unggul terhadap dua indikator standar nasional pendidikan (Standar Pendidik dan Tenaga Kependidikan, dan Standar Sarana dan Prasarana) adalah SMA Negeri 2 Ratahan, SMA Advent Ratahan, SMA Negeri 1 Pusomaen, SMA Kristen Ratatotok, SMA Muhammadiyah Ratatotok, SMK Muhammadiyah Ratatotok, SMK Nasional Molompar.Sekolah yang dikatakan unggul pada jumlah dan luas ruang kelas, jumlah LCD juga jumlah buku dalam perpustakaan adalah SMK N 1 Ratahan.
\end{abstract}

Kata kunci: Analisis Biplot, Standar Nasional Pendidikan

\section{Mapping SMA/SMK In Southeast Minahasa Regency Based On Four Indicators Of National Education Standards Using Biplot Analysis}

\begin{abstract}
Biplot analysis is a descriptive statistical analysis of multiple dimensions simultaneously serving the object of observation $n$ and $p$ variables in a graph on a two-dimensional plane, so that the characteristics and relative position of these variables can be analyzed. The purpose of this research is: 1) to describe the characteristics / quality of SMA / SMK in Southeast Minahasa Regency based on four indicators of national education standards, namely: Content Standards, Standards of Teachers and Education staff, Facilities and Infrastructure Standards and Management Standards; 2) mapping, both advantages and drawbacks of SMA / SMK in Southeast Minahasa Regency by standard indicators of National Education using Biplot Analysis. The research data was obtained from a population of 15 SMA / SMK in Southeast Minahasa Regency. Variable used were the Content Standards, Standards of Teachers and Education staff, Facilities and Infrastructure Standards and Management Standards. Data analysis was performed using Statistical software program. The results showed that the schools are categorized has having a good standard on the four indicators of national education standards, SMAN 1 Ratahan, SMK N 1 Ratahan, SMK N 1 Pusomaen, SMAN 1 Touluaan, SMK N 1 Touluaan, SMAN 1 Tombatu, SMK Kristen Tombatu, SMAN 1 Belang. While schools that are categorized poor standard of the fourth indicator of the national standards is SMA Negeri 2 Ratahan, SMA Advent Ratahan, SMA Negeri 1 Pusomaen, SMA Kristen Ratatotok, SMA Muhammadiyah Ratatotok, SMK Muhammadiyah Ratatotok, SMK Nasional Molompar.Schools are said to be superior to the amount and a vast of class room, amount of LCD, amount of books in library is SMKN 1 Ratahan.
\end{abstract}

Keywords: Biplot Analysis, National Education Standards 


\section{Pendahuluan}

Dalam UUD 1945 alinea keempat yang berisikan cita-cita bangsa Indonesia yakni mencerdaskan kehidupan bangsa karena bangsa yang cerdas adalah bangsa yang kuat. tujuan pendidikan nasional yaitu untuk mengembangkan potensi peserta didik agar menjadi manusia yang beriman dan bertakwa kepada Tuhan Yang Maha Esa, berakhlak mulia, sehat, berilmu, cakap, kreatif, mandiri, dan menjadi warga negara yang demokratis serta bertanggung jawab [1].

Untuk mewujudkan tujuan pendidikan nasional, pemerintah menetapkan 8 Standar Nasional yaitu Standar Kompetensi Lulusan, Standar Isi, Standar Proses, Standar Pendidikan dan Tenaga Kependidikan, Standar Sarana dan Prasarana, Standar Pengelolaan, Standar Pembiayaan Pendidikan dan Standar Penilaian Pendidikan. Dalam Penelitian ini hanya meneliti empat standar nasional pendidikan dari delapan standar yang ada, keempat standar pendidikan nasional itu adalah Standar Isi, Standar Pendidikan dan Tenaga Kependidikan, Standar Sarana dan Prasarana, dan Standar Pengelolaan.

Penelitian terdahulu pernah dilakukan di Kabupaten Minahasa Tenggara dengan menggunakan analisis biplot. Pada penelitian yang dilakukan yakni pada SMP dengan menggunakan keempat standar nasional tersebut dari delapan komponen standar nasional pendidikan [2].

Analisis biplot adalah salah satu bagian dari analisis peubah ganda (APG) yang dapat menyajikan secara simultan dalam bentuk gambar dua dimensi antara indikator standar isi, standar pendidik dan tenaga kependidikan, standar sarana dan prasarana, standar pengelolaan (sebagai peubah) dengan SMA/SMK yang ada di Kab. Minahasa Tenggara(sebagai objek).

Tujuan penelitian ini yaitu untuk memetakan keunggulan dan kekurangan dari SMA/SMK di Kabupaten Minahasa Tenggara berdasarkan empat indikator standar nasional pendidikan dengan menggunakan analisis biplot.

\section{Analisis Biplot}

Analisis statistika deskriptif dimensi ganda yang menyajikan secara simultan $n$ objek pengamatan dan $p$ peubah dalam suatu grafik pada suatu bidang dua dimensi, sehingga ciri-ciri dan posisi relatif peubah tersebut dapat dianalisis dinamakan Analisis Biplot [3].

Empat hal penting yang dapat dilihat pada biplot adalah :

1. Hubungan (korelasi) antar peubah, dengan menggunakan biplot peubah akan digambarkan sebagai garis berarah. Dua peubah yang memiliki korelasi positif tinggi akan digambarkan sebagai dua buah garis dengan arah yang sama, atau membentuk sudut yang sempit. Apabila dua peubah yang memiliki korelasi negatif tinggi akan digambarkan dalam bentuk dua garis yang arahnya berlawanan, atau membentuk sudut yang lebar (tumpul). Sedangkan dua buah peubah yang tidak berkorelasi akan digambarkan dalam bentuk dua garis yang mendekati $90^{\circ}$ (siku-siku).

2. Keragaman peubah, informasi ini digunakan untuk melihat apakah ada peubah tertentu yang nilainya hampir sama setiap objek ada yang sama besar dan ada juga yang sangat kecil. Dengan informasi ini, bisa diperkirakan pada peubah mana strategi tertentu harus ditingkatkan, serta sebaliknya.Dalam biplot, peubah dengan keragaman kecil digambarkan dengan vektor yang pendek, sedangkan peubah yang ragamnya besar digambarkan sebagai vektor yang panjang.

3. Kedekatan antar objek, informasi ini bisa dijadikan panduan objek mana yang memiliki kemiripan karakteristik dengan objek tertentu. Dalam biplot, dua objek dengan karakteristik sama akan digambarkan sebagai dua titik yang posisinya berdekatan.

4. Nilai peubah pada suatu objek, informasi ini digunakan untuk melihat keunggulan dari setiap objek. Objek yang terletak searah dengan arah dari suatu peubah dikatakan bahwa pada objek tersebut nilainya diatas rata-rata. Sebaliknya jika objek lain terletak berlawanan dengan arah dari peubah tersebut maka objek tersebut memiliki nilai dekat dengan rata-rata [4].

Analisis biplot didasarkan pada penguraian nilai-nilai singular suatu matriks. Penguraian nilai singular dari suatu matriks merupakan teorema dasar yang banyak digunakan dalam perhitungan matriks. Definisi dari SVD adalah suatu matriks $X$ yang merupakan matriks data dengan $n$ objek dan $p$ peubah diuraikan menjadi:

$$
X=U L A^{\prime}
$$

Matriks $U$ dan $A$ adalah matriks berukuran $(n x r)$ dan $(p x r)$ sedemikian sehingga

$U^{\prime} U=A^{\prime} A=I_{r}$ (matriks identitas berdimensi r). $L$ adalah matriks diagonal berukuran

$\left(\begin{array}{lll}r & x & r\end{array}\right)$ yang unsur-unsur diagonalnya merupakan akar pangkat dua dari akar ciri $X^{\prime} X$ sehingga $\sqrt{\lambda_{1}} \geq \sqrt{\lambda_{2}} \geq \ldots \geq \sqrt{\lambda_{r}}$. dengan $\lambda_{\mathrm{i}}$ adalah akar ciri dari matriks $X^{\prime} X$. Unsur-unsur diagonal dari matriks $L$ 
disebut nilai singular matriks $X$ dan kolom- kolom matriks $A$ adalah vektor ciri dari $X^{\prime} X$ yang berpadanan dengan $\lambda$. Dengan penjabaran persamaan (1) menjadi:

untuk $0 \leq \alpha \leq 1$,

$$
X=U L^{\alpha} L^{1-\alpha} A^{\prime}
$$

jika definisikan $G=U L^{\alpha}$ dan $H^{\prime}=L^{1-\alpha} A^{\prime}$, persamaan (2) dapat ditulis: $X=G H^{\prime}$

Keakuratan dari biplot dalam menerangkan tingkat keragaman dari matriks data asal dirumuskan sebagai berikut:

$$
\rho=\frac{\left(\lambda_{1}+\lambda_{2}\right)}{\sum_{k=1}^{p} \lambda_{K}}
$$

dimana : $\lambda_{1}=$ akar ciri terbesar pertama; $\lambda_{2}=$ akar ciri terbesar kedua; $\lambda_{\mathrm{k}}=$ akar ciri terbesar ke-k; $\rho=$ tingkat keakuratan. Jika $\rho$ semakin mendekati nilai satu maka biplot penyajiannya semakin baik dalam memberikan informasi [5].

\title{
3. Metodologi Penelitian
}

Data yang digunakan dalam penelitian ini berasal dari data primer tahun 2015. Data primer diambil pada seluruh SMA/SMK di Kabupaten Minahasa Tenggara (15 SMA/SMK). Data sekunder juga diambil di Dinas Pendidikan Pemuda dan Olahraga Kabupaten Minahasa Tenggara pada bulan JanuariFebruari 2015.

\subsection{Waktu dan Tempat Penelitian}

Data yang akan digunakan dalam penelitian ini berasal dari data primer (berupa Kuesioner) tahun 2015. Data primer diambil pada seluruh SMA/SMK di Kabupaten Minahasa Tenggara (15 SMA/SMK). Data primer yang diambil merupakan data populasi SMA/SMK di Kabupaten Minahasa Tenggara. Data sekunder juga diambil di Dinas Pendidikan dan Olahraga Kabupaten Minahasa Tenggara pada bulan Januari-Februari 2015.

\subsection{Objek Penelitian}

Objek dari penelitian ini adalah 15 SMA/SMK yaitu:
1. SMAN 1 Ratahan (A1)
2. SMAN 2 Ratahan (A2)
3. SMA Advent Ratahan (A3)
4. SMKN 1 Ratahan (A4)
5. SMAN 1 Pusomaen (A5)
6. SMKN 1 Pusomaen (A6)
7. SMAN 1 Touluaan (A7)
8. SMK N 1 Touluaan (A8)

\author{
9. SMAN 1 Tombatu (A9) \\ 10. SMK Kristen Tombatu (A10) \\ 11. SMAN 1 Belang (A11) \\ 12. SMA Kristen Ratatotok (A12) \\ 13. SMA Muh. Ratatotok (A13) \\ 14. SMK Muh. Ratatotok (A14) \\ 15. SMK Nasional Molompar (A15)
}

\subsection{Peubah Penelitian}

Peubah yang diamati yaitu sebagai berikut:

Tabel 1. Peubah Standar Isi (X1)

\begin{tabular}{|c|l|}
\hline Kode & \multicolumn{1}{|c|}{ Nama Peubah (Definisi) } \\
\hline $\mathrm{X} 11$ & Kurikulum yang digunakan \\
\hline
\end{tabular}

Tabel 2. Peubah Standar Pendidikan dan Tenaga Kependidikan (X2)

\begin{tabular}{|c|l|}
\hline Kode & \multicolumn{1}{|c|}{ Nama Peubah (Definisi) } \\
\hline X21 & Jumlah dan kualifikasi masing-masing guru (D3, D4/S1, S2, S3) \\
\hline X22 & Kualifikasi kepala sekolah (D3 / S1 / S2) \\
\hline X23 & Jumlah dan kualifikasi tenaga administrasi (SMA, D1, D2, D3, S1) \\
\hline X24 & Jumlah dan kualifikasi tenaga perpustakaan (SMA, D1, D2, D3, S1) \\
\hline X25 & Jumlah dan kualifikasi tenaga laboratorium (SMA, D1, D2, D3, S1) \\
\hline X26 & Jumlah dan kualifikasi tenaga kebersihan \\
\hline
\end{tabular}


Tabel 3. Peubah Standar Sarana dan Prasarana (X3)

\begin{tabular}{|c|l|}
\hline Kode & \multicolumn{1}{|c|}{ Nama Peubah (Definisi) } \\
\hline X31 & Luas lahan \\
\hline X32 & Jumlah dan luas ruang kelas \\
\hline X33 & Jumlah LCD \\
\hline X34 & Jumlah dan luas ruang perpustakaan \\
\hline X35 & Jumlah buku dalam ruang perpustakaan \\
\hline X36 & Jumlah dan luas laboratorium IPA \\
\hline X37 & Jumlah perlengkapan dalam laboratorium \\
\hline X38 & Jumlah dan luas laboratorium komputer \\
\hline X39 & Jumlah komputer \\
\hline X310 & Jumlah dan luas ruang pimpinan \\
\hline X311 & Jumlah dan luas ruang guru \\
\hline X312 & Jumlah dan luas ruang tata usaha \\
\hline X313 & Jumlah dan luas ruang beribadah \\
\hline X314 & Jumlah dan luas ruang konseling \\
\hline X315 & Jumlah dan luas ruang UKS \\
\hline X316 & Jumlah dan luas ruang organisasi kesiswaan \\
\hline X317 & Jumlah dan luas WC \\
\hline X318 & Jumlah dan luas lapangan olahraga \\
\hline
\end{tabular}

Tabel 4. Peubah Standar Pengelolaan (X4)

\begin{tabular}{|c|l|}
\hline Kode & \multicolumn{1}{c|}{ Nama Peubah (Definisi) } \\
\hline X41 & Pengelolaan untuk perencaaan program \\
\hline X42 & Pengelolaan untuk pelaksanaan rencana sekolah \\
\hline X43 & Pengelolaan untuk pengawasan dan evaluasi \\
\hline
\end{tabular}

\subsection{Metode Analisis}

Metode analisis yang dilakukan dengan analisis biplot dengan langkah- langkah sebagai berikut :

1. Pemasukan data (matriks data X) (dengan perangkat lunak Statistika untuk menstandarisasi matriks data X).

2. Standarisasi matriks $X$ (dengan perangkat lunak Statistika untuk menstandarisasi matriks dara $X$ ).

3. Penguraian matriks $X$ yang telah distandarisasi dengan SVD.

4. Penghitungan matriks $\mathrm{H}=\mathrm{AL}$ dan $\mathrm{G}=\mathrm{UL}$.

5. Plot matriks $\mathrm{G}$ dan $\mathrm{H}$ secara tumpang tindih.

Langkah 3,4,dan 5 dilakukan dengan menggunakan perangkat lunak Statistika yaitu Analisis Biplot.

\section{Hasil dan Pembahasan}

Dalam Analisis Biplot ini hanya menggunakan dua Standar Nasional Pendidikan yaitu Standar Pendidik dan Tenaga Kependidikan (X2) dan Standar Sarana dan Prasarana (X3) sementara untuk kedua Standar lainnya yakni Standar Isi (X1) dan Standar Pengelolaan (X4), tidak digunakan dalam Analisis Biplot karena nilai dari kedua standar tersebut sama untuk semua SMA/SMK Jadi kedua peubah (X1 dan X4) tidak mempunyai ragam atau bisa dikatakan bahwa tingkat keragamannya nol.

Setelah menjalankan program makro biplot dan input data melalui perangkat lunak Statistika, maka diperoleh hasil yaitu :

\subsection{Plot antara Peubah Standar Pendidik dan Tenaga Kependidikan (X2) dengan Objek Pengamatan}

Berdasarkan gambar 1 dapat dilihat bahwa keragaman yang diterangkan oleh dimensi 1 sebesar $31.8 \%$ dan dimensi 2 sebesar $24.6 \%$ sehingga total keragaman sebesar 56.4\%. Rasio skala yang digunakan dalam biplot adalah 1 . 


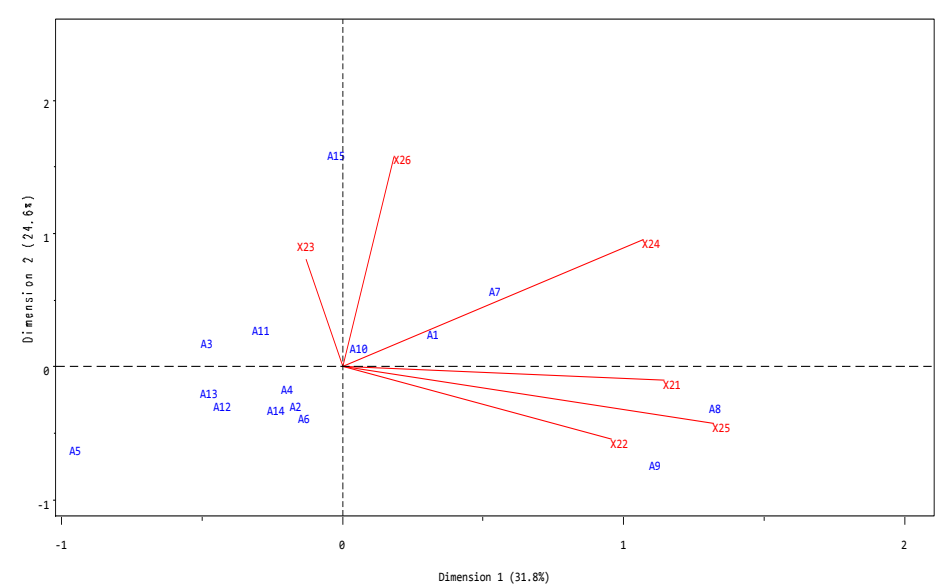

Gambar 1. Plot antara standar pendidik dan tenaga kependidikan (X2) dengan objek pengamatan

Peubah standar pendidik dan tenaga kependidikan yaitu pada jumlah dan kualifikasi guru (X21), jumlah dan kualifikasi tenaga perpustakaan (X24), dan jumlah dan kualifikasi tenaga laboratorium (X25) memiliki vektor yang lebih panjang dibanding 3 vektor yang lain dari keenam vektor yang ada. Hal ini menunjukan bahwa jumlah dan kualifikasi guru (X21), jumlah dan kualifikasi tenaga perpustakaan (X24), serta jumlah dan kualifikasi tenaga laboratorium (X25) sangatlah beragam pada SMA/SMK yang ada di Kabupaten Minahasa Tenggara. Dengan nilai akar ciri terbesar pertama 5.1694, akar ciri terbesar kedua 4.5496 maka dengan menggunakan persamaan 3 diperoleh nilai $\rho=0.4513$, dari nilai $\rho$ ini dapat dijelaskan bahwa sebesar 0.4513 atau 0.5 keakuratan dari biplot dalam menerangkan tingkat keragaman dari matriks data asal memberikan penyajian yang cukup baik.

Dari gambar 1 juga dapat dijelaskan bahwa SMK N 1 Ratahan (A4), SMAN 2 Ratahan (A2), SMK N 1 Pusomaen (A6), dan SMK Muh Ratatotok (A14) memiliki jarak antar objek yang berdekatan. Hal ini menunjukan bahwa karakteristik standar tenaga pendidik dan tenaga kependidikan keempat objek tersebut relatif sama. Sama halnya dengan SMA Kristen Ratatotok (A12) dan SMA Muhammadiyah Ratatotok (A13) yang juga berdekatan.

Dalam tampilan biplot terlihat bahwa SMK Negeri 1 Touluaan (A8) unggul padakualifikasi pendidikan kepala sekolah (X22), karena vektor dua peubah tersebut searah dengan objek A8. Sementara untuk SMAN 1 Tombatu (A9) unggul dalam jumlah dan kualifikasi guru (X21), karena vektor peubah (X21) searah dengan objek (A9), dan juga unggul pada kualifikasi pendidikan kepala sekolah (X22), serta pada jumlah dan kualifikasi tenaga administrasi (X25). Sama halnya dengan SMAN 1 Touluaan (A7) yang unggul dalam jumlah dan kualifikasi tenaga perpustakaan (X24), karena vektor peubahnya memiliki arah yang sama dengan objek pengamatan (A7).

\subsection{Plot antara Peubah Standar Sarana dan Prasarana dengan Objek Pengamatan}

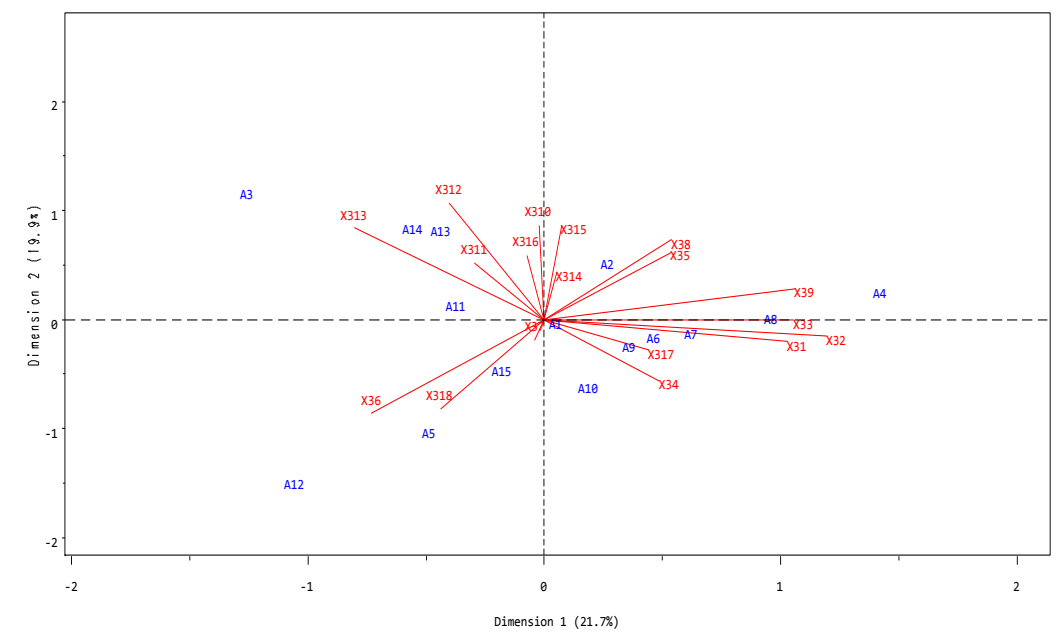

Gambar 2. Plot antara standar Sarana dan Prasarana dengan objek pengamatan 
Informasi yang diperoleh dari gambar 2 dapat dijelaskan bahwa dengan keragaman dimensi satu sebesar $21.7 \%$ dan dimensi dua sebesar $19.9 \%$ maka diperoleh total keragamannya adalah $41.6 \%$, rasio skala yang digunakan dalam biplot adalah 1 . Peubah standar sarana dan prasarana yaitu pada luas lahan sekolah (X31), jumlah dan luas ruang kelas (X32), jumlah LCD (X33), jumlah dan luas laboratorium IPA (X36), jumlah komputer (X39), dan jumlah dan luas ruang beribadah (X313) dimana keenam peubah tersebut memiliki vektor yang lebih panjang dibanding vektor - vektor yang lain. Hal ini menunjukan bahwa luas lahan sekolah (X31), jumlah dan luas ruang kelas (X32), jumlah LCD (X33), jumlah dan luas laboratorium IPA (X36), jumlah komputer (X39), dan jumlah dan luas ruang beribadah (X313) sangatlah beragam pada SMA/SMK yang ada di Kabupaten Minahasa Tenggara.

Dengan menggunakan persamaan 3 diperoleh nilai $\rho=0.28236$, dengan nilai akar ciri terbesar pertama 7.3987, akar ciri terbesar kedua 7.0864 dari nilai $\rho$ yang telah dihitung dapat dijelaskan bahwa sebesar 0.28236 atau 0.3 keakuratan dari biplot dalam menerangkan tingkat keragaman dari matriks data asal memberikan penyajian yang cukup baik.

Berdasarkan gambar 2 dapat dijelaskan bahwa kedekatan antar objek ditunjukan oleh SMK N 1 Pusomaen (A6), SMAN 1 Touluaan (A7), dan SMAN 1 Tombatu (A9) karena jarak ketiga objek yang berdekatan. Hal ini menunjukan bahwa karakteristik standar sarana dan prasarana ketiga objek tersebut relatif sama.

Pada tampilan biplot terlihat bahwa SMA Kristen Tombatu (A10) unggul pada luas lahan sekolah (X31) karena vektor peubah tersebut searah dengan objek A10. Begitu juga dengan SMK N 1 Ratahan (A4) terlihat unggul pada jumlah dan luas ruang kelas (X32), jumlah LCD (X33) juga jumlah buku dalam perpustakaan (X35).

\subsection{Plot antara 2 Peubah (Standar Pendidik dan Tenaga Kependidikan dan Standar Sarana dan Prasarana) dengan Objek Pengamatan}

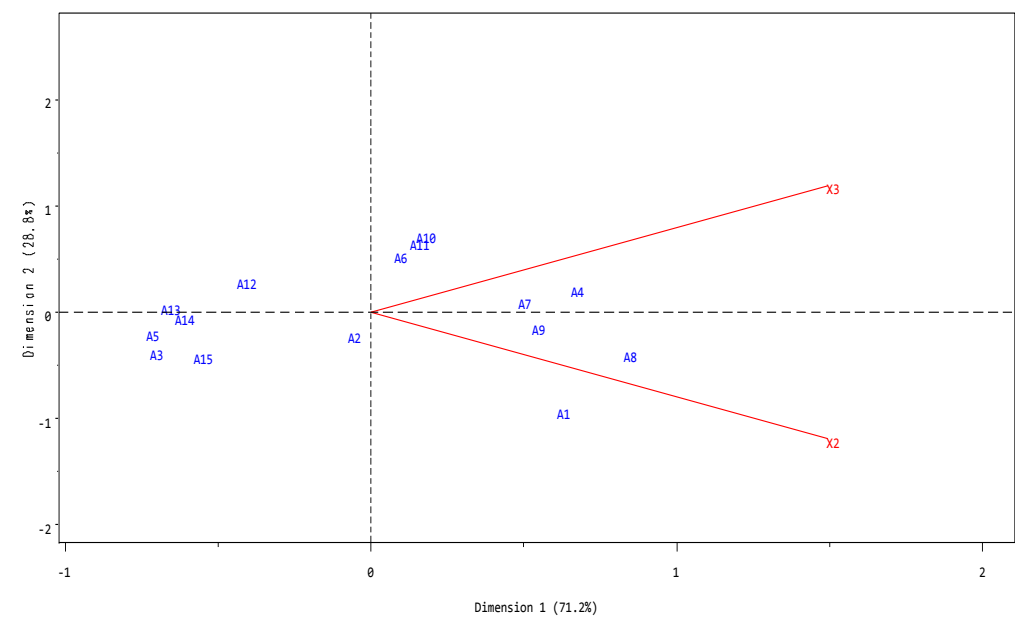

Gambar 3. Plot antara 2 Peubah (X2,X3) dengan Objek Pengamatan

Gambar 3 memperlihatkan bahwa keragaman yang diterangkan oleh dimensi 1 sebesar $71.2 \%$ dan dimensi 2 sebesar $28.8 \%$ sehingga total keragaman sebesar 100\%. Rasio skala yang digunakan dalam biplot adalah 1. Kedua peubah standar Nasional Pendidikan yaitu peubah standar pendidik dan tenaga kependidikan (X2), dan peubah standar sarana dan prasarana (X3) memiliki keragaman yang sama besar karena memiliki vektor yang sama panjang. Hal ini menunjukkan bahwa SMA/SMK yang ada di Kabupaten Minahasa Tenggara sangat beragam dalam peubah standar pendidik dan tenaga kependidikan juga dalam standar sarana dan prasarana.

Dengan menggunakan persamaan 3 diperoleh nilai $\rho=1$ dengan nilai akar ciri terbesar pertama 4.4661, akar ciri terbesar kedua 2,8379 dari nilai $\rho$ yang telah dihitung dapat dijelaskan bahwa keakuratan dari biplot dalam menerangkan tingkat keragaman dari matriks data asal rnemberikan penyajian yang sangat baik.

Berdasarkan gambar 3 juga dapat dijelaskan bahwa kedekatan antar objek ditunjukan oleh SMK Negeri 1 Pusomaen (A6) dan SMK Kristen Tombatu (A10), dan SMA Negeri 1 Belang (A11), karena jarak ketiga objek yang berdekatan. Hal ini menunjukan bahwa karakteristik standar tenaga pendidik dan tenaga kependidikan dan juga standar sarana dan prasarana kedua objek tersebut dapat dikatakan relatif 
sama. Demikian halnya dengan SMA Muhammadiyah Ratatotok (A13) dan SMK Muhammadiyah Ratatotok (A14) dan juga SMA Advent Ratahan (A3) dengan SMA Negeri 1 Pusomaen (A5) yang saling berdekatan.

Dapat dilihat juga bahwa SMK Negeri 1 Touluaan (A8) unggul pada peubah standar pendidik dan tenaga kependidikan (X2) di semua SMA/SMK. Sementara mengikutinya untuk SMA Negeri 1 Ratahan (A1) dapat dikatakan sedikit unggul pada peubah standar pendidik dan tenaga kependidikan (X2) karena vektor peubah tersebut searah dengan objek A8 maupun A1. Dan juga SMK Negeri 1 Ratahan (A4) unggul pada peubah standar sarana dan prasarana (X3).

Dalam gambar 3 juga dapat dilihat bahwa ada objek-objek yang terbagi pada kedua sisi dimensi 2 namun tidak satupun vektor peubah yang mengarah ke objek- objek disebelah kiri dimensi 2. Hal ini berarti objek-objek yang terletak disebelah kiri dimensi 2 itu memiliki standar yang kurang unggul terhadap peubah standar tenaga pendidik dan tenaga kependidikan (X2) dan juga standar sarana dan prasarana (X3). Objek - objek tersebut yaitu SMAN 2 Ratahan (A2), SMA Advent Ratahan (A3), SMAN 1 Pusomaen (A5), SMA Kristen Ratatotok (A12), SMA Muh. Ratatotok (A13), SMK Muh. Ratatotok (A14), SMK Nasional Molompar (A15).

\subsection{Plot antara 2 Peubah (Standar Pendidik dan Tenaga Kependidikan dan Standar Sarana dan Prasarana (X3a,X3b,X3c) dengan Objek Pengamatan.}

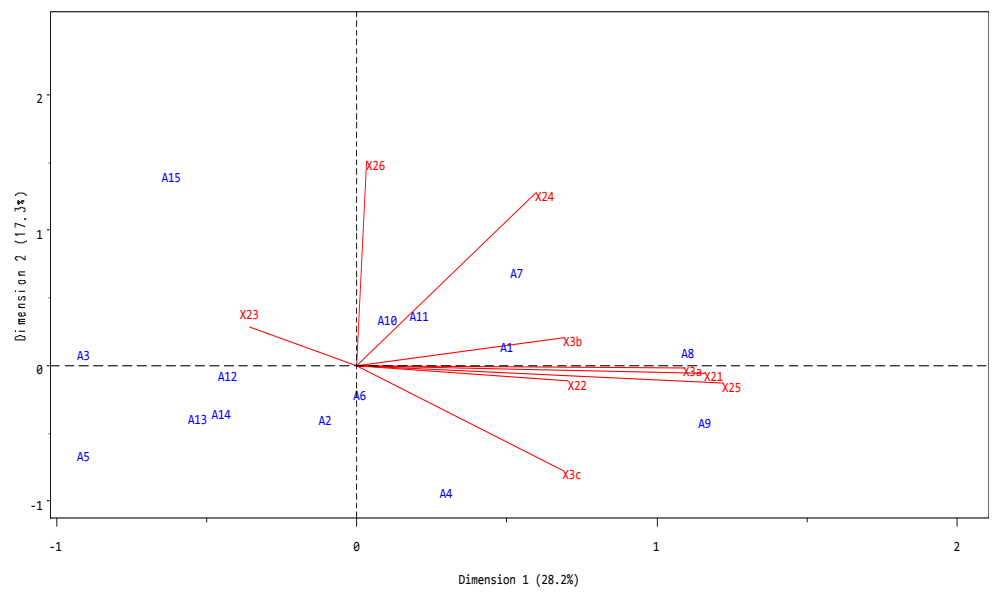

Gambar 4. Plot antara 2 Peubah dengan Objek Pengamatan

Berdasarkan gambar 4, dapat dijelaskan bahwa keragaman yang diterangkan oleh dimensi 1 sebesar $17.3 \%$ dan dimensi 2 sebesar $28.2 \%$ sehingga total keragaman sebesar 45,5\%. Rasio skala yang digunakan dalam biplot adalah 1. Peubah standar pendidik dan tenaga kependidikan (X2) memiliki keragaman yang besar karena memiliki vektor yang panjang yakni pada (X21 dan X25). Hal ini menunjukkan bahwa SMA/SMK yang ada di Kabupaten Minahasa Tenggara sangat beragam dalam peubah standar pendidik dan tenaga kependidikan dibanding dengan peubah standar sarana dan prasarana. Selanjutnya dengan menggunakan nilai akar ciri terbesar pertama yakni 5.9617 dan nilai akar ciri terbesar kedua yakni 4.6709 maka diperoleh nilai $\rho$ berdasarkan persamaan 3 yaitu $\rho=0.3393$ atau 0.3 keakuratan dari biplot dalam menerangkan tingkat keragaman dari matriks data asal memberikan penyajian yang cukup baik. Gambar 4 juga menerangkan bahwa adanya objek yang memiliki jarak berdekatan yakni SMA Muh. Ratatotok (A13) dan SMK Muh. Ratatotok (A14), kedua sekolah ini menjelaskan bahwa adanya karakteristik standar pendidik dan tenaga kependidikan khususnya (X23) yaitu jumlah dan kualifikasi tenaga administrasi yang sama, hal ini memang benar karena kedua sekolah ini memiliki kepengurusan yayasan muhammadiyah yang sama. Demikian pula dengan SMK Kristen Tombatu (A10) dan SMAN 1 Belang (A11) yang memiliki karakteristrik hampir sama.

Pada tampilan biplot terlihat bahwa SMA Negeri 1 Tombatu (A9) unggul pada jumlah dan kualifikasi tenaga administrasi (X25) karena vektor peubah tersebut searah dengan objek A9. Begitu juga dengan SMA N 1 Ratahan (A1) terlihat unggul pada jumlah dan luas sarana-prasarana laboratorium (X3b). 


\section{Kesimpulan}

Berdasarkan plot peubah standar pendidik dan tenaga kependidikan, SMAN 1 Tombatu unggul dalam jumlah dan kualifikasi guru, dan juga unggul pada kualifikasi pendidikan kepala sekolah, serta pada jumlah dan kualifikasi tenaga administrasi. Berdasarkan plot peubah standar sarana dan prasarana, SMK N 1 Ratahan terlihat unggul pada jumlah dan luas ruang kelas, jumlah LCD juga jumlah buku dalam perpustakaan. Berdasarkan plot antara 2 peubah (standar pendidik dan tenaga kependidikan, dan standar sarana dan prasarana) dengan objek pengamatan, sekolah-sekolah yang dikategorikan telah memiliki keunggulan terhadap dua indikator standar nasional pendidikan adalah SMA Negeri 1 Ratahan, SMK Negeri 1 Ratahan, SMK Negeri 1 Pusomaen, SMA Negeri 1 Touluaan, SMK Negeri 1 Touluaan, SMA Negeri 1 Tombatu, SMK Kristen Tombatu, SMA Negeri 1 Belang. Sedangkan SMA/SMK yang dikategorikan memiliki standar yang kurang unggul terhadap dua indikator standar nasional pendidikan adalah SMA Negeri 2 Ratahan, SMA Advent Ratahan, SMA Negeri 1 Pusomaen, SMA Kristen Ratatotok, SMA Muhammadiyah Ratatotok, SMK Muhammadiyah Ratatotok, SMK Nasional Molompar.

\section{Daftar Pustaka}

[1] Undang-Undang Republik Indonesia Nomor 20 Tahun 2003 Tentang Sistem PendidikanNasional.

[2] Daman. R. dan D.Hatidja. 2012. Pemetaan SMP- SMP di Kabupaten Minahasa Tenggara, Sulawesi Utara berdasarkan Standar Pendidikan dan Tenaga Kependidikan, Standar Sarana dan Prasarana, Standar Pengelolaan dan Standar Pembiayaan Pendidikan dengan Menggunakan Analisis Biplot. De Cartesian. 1(1): 27 - 33.

[3] Joliffe, I.T. 1986. Principal Component Analysis.Springer. Verlag. New York.

[4] Mattjik,A.A., M.Sumertajaya, Wijayanto, Indahwati, A. Kurnia,.B. Sartono. 2004. Modul Teori Pelatihan Analisis Multivariat. Departemen Statistika FMIPA IPB, Bogor.

[5] Everit, B. 1978. Graphical Techniques for Multivariate Data. Heinermann Educational Books. 